\title{
Crescimento e Desenvolvimento do Dossel de Panicum maximum cv. Mombaça ${ }^{1}$
}

\author{
Emerson Alexandrino², José Alberto Gomide ${ }^{3}$, Carlos Augusto de Miranda Gomide ${ }^{4}$
}

RESUMO - Em duas áreas de $1.200 \mathrm{~m}^{2}$ de capim Panicum maximum cv. Mombaça, acompanhou-se a evolução do perfilhamento, da biomassa, do índice de área foliar (IAF), da interceptação da radiação fotossinteticamente ativa (IRFA) e da eficiência de uso da radiação (EUR) no verão e outono. Para melhor compreesão do crescimento do dossel, realizou-se também análise do crescimento, estimando-se a taxa de crescimento relativo (TCR), a taxa assimilatória líquida (TAL) e a razão de área foliar (RAF) da gramínea. Para todas as variáveis,

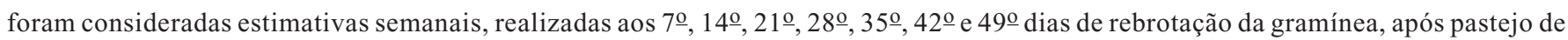
uniformização. Utilizou-se delineamento experimental inteiramente casualizado, com quatro repetições e duas áreas experimetais: uma no verão e outra no outono. No verão e no outono, foram visualizados, respectivamente, 28 e 24 pontos, sorteados pelos tratamentos experimentais, semelhantes quanto à altura do dossel e à cobertura do solo, após intenso pastejo de uniformização. O perfilhamento da gramínea, intenso na primeira semana, decresceu nas duas semanas seguintes e praticamente cessou a partir da quarta semana. A IRFA evoluiu assintoticamente, atingindo valores de $96 \%$ em ambas as estações. O IAF apresentou o mesmo padrão de resposta, com valores de 8 e 4 no verão e no outono, respectivamente. Em ambas as estações, a biomassa evoluiu de forma quadrática com o decorrer da rebrotação. A EUR, mais alta no verão que no outono, decreceu e seus respectivos valores foram 1,76 e 0,54gMS/MJ, em razão da menor precipitação pluviométrica desse período. A eficiência de crescimento do dossel, medida pela TCR, mais alta no verão que no outono e decresceu assintoticamente durante a rebrotação, em ambos os períodos. Enquanto a TAL reduziu durante o período de rebrotação, a RAF aumentou até um ponto de máximo, tanto no verão como no outono, decrescendo posteriormente.

Palavras-chave: índice de área foliar, interceptação da radiação, perfilhamento, razão de área foliar, taxa assimilatória líquida, taxa de crescimento relativo

\section{Canopy Growth and Development of Panicum maximum "cv" Mombaça}

ABSTRACT - It was assessed the evolution of tillering, forage biomass, leaf area index (LAI), interception of photosynthetically active radiation (IPAR), efficiency of radiation use (ERU) in Panicum maximum "cv" Mombaça during the regrowth period of the grass, in the Summer and Autumn seasons. Similarly, grass growth indices were assessed: net assimilation rate (NAR), leaf area ratio (LAR) and relative growth rate (RGR). All these variables were estimated from field observations taken on the $7^{\text {th }}, 14^{\text {th }}, 21^{\text {st }}, 28^{\text {th }}, 35^{\text {th }}, 42^{\text {nd }}$ and $49^{\text {th }}$ days of the regrowth period (treatments), in the Summer and Autumn seasons. The experimental design was completely randomized with four replications. One area of $1,200 \mathrm{~m}^{2}$ was used in each season; 28 and 24 sampling points were chosen in the Summer and the Autunm seasons, respectively, for their similarity regarding canopy height and soil cover condition and randomly assigned to the treatments. The grass tillering was more intense in the first regrowth week and declined afterwards to reach negligible values from the fourth week on. Interception of the photosynthetically active radiation evolved in an asymptotic manner reaching highest value of $96 \%$, without difference between Summer and Autumn. Leaf area index figures showed the same pattern in the Summer and Autumn, reaching the values of 8 and 4, respectively; on the other hand, forage biomass responded quadractically to the duration of the regrowth period. Radiation use efficiency reached the values of 1.76 and $0.54 \mathrm{gDM} / \mathrm{MJ}$ in Summer and Autumn, respectively. RGR and NAR figures decreased in an asymptotic pattern in both seasons, with higher values in the Summer, while LAR figures increased initially in the first four weeks reaching values of 0.017 and $0.013 \mathrm{~m}^{2} / \mathrm{g}$ towards the $28^{\text {th }}$ day of the regrowth period, respectively in Autumn and Summer.

Key Words: interception of photosynthetically active radiation, leaf area index, leaf area ratio, rate of net assimilation, rate of relative growth, tillering

\section{Introdução}

A produção de biomassa de forragem é o principal componente que define a capacidade de suporte das pastagens; daí a relevância do conhecimento de seus componentes para se compreender como as estratégias de manejo (adubação, irrigação, ajuste da carga animal e outros) os influenciam. A produção de biomassa é influenciada por fatores extrínsecos, como radiação, temperatura, umidade do solo e outros, e

${ }_{1}^{1}$ Parte da tese do primeiro autor; pesquisa financiada pela FAPEMIG.

2 Professor Adjunto de Nutrição e Pastagem do Departamento de Agronomia, Universidade Federal de Rondônia, Campus de Rolim de Moura, Avenida Norte Sul, 7300, Bairro Nova Morada, Rolim de Moura, Rondônia, CEP: 78987-000.

3 Bolsista do CNPq (jagomide@ufv.br).

${ }^{4}$ Engenheiro Agrônomo, pesquisador Embrapa - CNPGL - Juiz de Fora-MG. 
intrínsecos ao dossel, destacando-se a eficiência de captação e utilização dos recursos disponíveis. Matematicamente, a produção de biomassa é estimada considerando-se a intensidade da radiação fotossinteticamente ativa incidente (RFA) interceptada, a eficiência de uso desta radiação (EUR) e o índice de colheita (IC) (McKenzie et al., 1999). A RFA incidente é o único parâmetro do modelo que não é influenciado pelas estratégias de manejo.

A interceptação da RFA mantém estreita relação com vários fatores, como índice de área foliar (IAF) (Pearce et al., 1965), ângulo foliar (Sheehy \& Cooper, 1973; Sugyiama et al., 1985) e propriedades óticas das folhas. No início do desenvolvimento, cada incremento em IAF representa incremento proporcional em IRFA, mas, posteriormente, decresce o incremento da IRFA em resposta ao incremento do IAF (Cândido et al., 2005). O IAF é determinado pelas condições de ambiente, uma vez que elas influenciam as características estruturais do dossel (Lemaire, 1997). Contudo, o manejo tem papel fundamental na evolução do IAF ao determinar diretamente a área foliar residual e, indiretamente, o IAF final, pela quantidade e qualidade da radiação que se distribui pelo perfil do dossel.

A EUR, outro importante parâmetro da produção de biomassa, que define a quantidade de massa produzida para cada unidade de radiação fotossinteticamente ativa interceptada, tem recebido pouca atenção em estudos sobre plantas forrageiras. Inúmeros são os fatores que determinam a EUR que, segundo Lê Roux et al., (1997), é raramente constante durante o ciclo da vegetação e pode variar conforme o estádio fenológico e as condições de ambiente. A EUR está diretamente relacionada à produção de folhas, à capacidade fotossintética das folhas e depende da partição de assimilados (Le Roux et al., 1997).

O índice de colheita, relação entre o produto de interesse econômico e a produção total de biomassa (Beadle, 1993), é um critério importante na avaliação de manejos alternativos de uma cultura. No manejo da pastagem, a folha é o produto econômico.

A análise de crescimento é ferramenta valiosa por facilitar a compreensão das adaptações morfofisiológicas da planta às condições de meio e manejo a que ela é submetida, definindo seu crescimento e desenvolvimento. Segundo Beadle (1993) e Radford (1967), apenas duas características são requeridas para uma análise simples de crescimento: o peso seco total da massa vegetal por unidade de área de solo e a dimensão do aparelho fotossintético por unidade de área de solo. Nesse tipo de estudo, interessam os seguintes índices fisiológicos: taxa de crescimento relativo (TCR), taxa assimilatória líquida (TAL) e os índices morfológicos razão de área foliar (RAF), razão de peso foliar (RPF) e área foliar específica (AFE) (Radford, 1967 e Bleade, 1993).

A TCR, índice de crescimento do dossel, é o produto do componente morfológico, a RAF, pelo componente fisiológico, a TAL. Cândido et al. (2005) observaram, em capim-mombaça, que a TCR apresentou comportamento decrescente com o avanço da rebrotação, variando de 0,17 a $0,02 \mathrm{~g} \cdot \mathrm{g}^{-1} \cdot \operatorname{dia}^{-1}$ do $5 \underline{\text { o }}$ ao $45^{\circ}$ dia, pós-pastejo. Contudo, Gomide \& Gomide (1999) constataram que esse valor foi bem mais elevado, em torno de $0,7 \mathrm{~g} \cdot \mathrm{g}^{-1} \mathrm{dia}^{-1}$, quando o capim-mombaça foi cultivado em vaso, com ausência de competição entre plantas, com irrigação e com adubação mais elevada, indicando que a TCR é bastante variável, e depende das condições de ambiente e manejo.

A RAF é o índice de relação do tamanho do aparelho fotossintético com a massa da planta. Valores de RAF para o capim-mombaça em torno de 0,023 a $0,012 \mathrm{~m}^{2} \mathrm{~g}^{-1}$ foram relatados por Cândido et al. (2005). Apesar de alguns estudos demonstrarem queda da RAF durante todo o período de rebrotação avaliada (Gomide et al., 2003; Oliveira et al., 2000), indicando translocação preferencial para as hastes, a prioridade da planta é a reconstituição da área foliar (AF) e, portanto, a RAF se eleva após a desfolhação até um ponto de máxima e, posteriormente, reduz no decorrer da rebrotação (Gomide et al., 2003). Assim, a área foliar residual define o comportamento da RAF durante a desfolhação.

A TAL representa o balanço entre a fotossíntese e respiração (Lambers, 1987) e pode ser positiva ou negativa, conforme as condições de meio e manejo a que a planta é submetida. Representa ainda a eficiência do aparelho fotossintético, pois reflete o acréscimo em massa por unidade de área foliar por dia. Segundo Cândido et al. (2005), a TAL estimada para o capim-mombaça sob condição de campo decresceu de 8,0 a 2,4 $\mathrm{g} \mathrm{m}^{-2} \mathrm{dia}^{-1}$, do início da rebrotação, após roçada, mas atingiu valores negativos nas rebrotações pós-pastejo subseqüentes.

Poorter (1989), avaliando o efeito da RAF e da TAL sobre a TCR em espécies herbáceas do tipo $\mathrm{C}_{3}$, incluindo gramíneas e leguminosas, observou correlação negativa e significativa, mas de pequena magnitude,

\section{R. Bras. Zootec., v.34, n.6, p.2164-2173, 2005 (supl.)}


entre TAL e TCR e positiva e altamente significativa entre TCR e RAF. Entretanto, esses resultados são controversos para as gramíneas tropicais, como os capim-mombaça (Cândido et al., 2005; Gomide et al., 2003) e o capim-tifton 85 (Oliveira et al., 2000), e parece ser dependente das condições a que planta é submetida.

A sazonalidade da produção de massa de forragem ao longo do ano é comumente enfocada como uma das causas da baixa produção animal ao longo do ano. Entretanto, no período das águas, quando aumenta o crescimento das forrageiras, existem situações em que o crescimento da planta tende a ser comprometido.

Este estudo foi realizado com os objetivos de avaliar a evolução do perfilhamento, do IAF, da IRFA, e da EUR durante a rebrotação do dossel de Panicum maximum cv. Mombaça no verão e no outono e analisar o crescimento, dando-se ênfase à TCR, à TAL e à RAF.

\section{Material e Métodos}

O experimento foi realizado na Central de Experimentação, Pesquisa e Extensão do Triângulo Mineiro (CEPET/UFV), localizada no município de Capinópolis, MG, situado a $18^{\circ} 41^{\prime}$ de latitude sul e $49^{\circ} 34^{\prime} \mathrm{de}$ longitude oeste.

Em uma pastagem de capim-mombaça, foram cercadas duas áreas de $1.200 \mathrm{~m}^{2}$, uma no verão e outra no outono, para o estudo da evolução da rebrotação do dossel dessa gramínea. O estudo de verão foi conduzido no período de 15/01/2002 a 06/03/ 2002 (50 dias) e o de outono, de 04/03/2002 a 16/04/ 2002 (43 dias), que correspondeu, em sua maior parte, ao outono. O estudo de cada área foi precedido por pastejo intenso, para remoção do excesso de sua vegetação. Ao início da rebrotação, cada área recebeu $250 \mathrm{~kg} / \mathrm{ha}$ de adubo da fórmula 20-05-20 como adubação de cobertura.
Durante a rebrotação, o dossel de cada área foi amostrado, em intervalos semanais, a partir do $7 \underline{0}$ dia, totalizando 7 e 6 colheitas (tratamentos) no verão e outono, respectivamente. Os pontos de amostragem eram representativos da condição média do dossel, quanto à altura da vegetação e à cobertura do solo no momento da saída dos animais.

O delineamento experimental foi de casualização completa, com quatro repetições (amostras) para o estudo de sete e seis idades de rebrotação, no verão e outono, respectivamente.

As condições de ambiente durante o período experimental foram registradas em uma estação meteorológica instalada a $50 \mathrm{~m}$ da área experimental (Tabela 1).

Os registros de insolação diária (brilho solar) foram convertidos em radiação, segundo Vianello \& Alves (2000), conforme a expressão da irradiância solarglobal:

$$
\mathrm{R}_{\mathrm{g}} \quad \mathrm{R}_{0} \square \mathrm{a} \square \mathrm{p} / \mathrm{N} \square
$$

em que: Rg - irradiância solar global diária sobre uma superfície horizontal, rente ao solo $\left(\mathrm{J} \mathrm{m}^{-2}\right)$; R0 irradiância solar global diária no topo da atmosfera $\left(\mathrm{J} \mathrm{m}^{-2}\right) ; \mathrm{a}, \mathrm{b}$ - coeficientes empíricos, obtidos por análise de regressão linear para determinada localidade; n - duração, em horas, do brilho solar; $\mathrm{N}$ - duração astronômica do período diurno (horas). Esse valor (Rg) foi multiplicado por 0,5 , para estimar a radiação fotossinteticamente ativa diária (RFAd) $\left(\mathrm{MJ} \mathrm{m}^{-2}\right)$. A partir dos valores obtidos, realizou-se o somatório da RFAd e obteve-se a radiação fotossinteticamente ativa total (RFAt) ao longo de cada período estudado.

Em cada data de amostragem, foram efetuadas quatro colheitas, a $20 \mathrm{~cm}$ do solo, da forragem contida em molduras de $1,0 \times 1,5 \mathrm{~m}$. O material amostrado foi levado ao laboratório e separado em lâmina foliar e

Tabela 1- Médias das temperaturas máxima, média e mínima da radiação fotossinteticamente ativa incidente (Rad Inc), da umidade relativa (UR) total de precipitação (Ppt) e da evaporação (Evap) na área experimental durante o verão e o outono de 2001

Table 1 - Average of temperatures: maximum, medium and minimum, interception of photosynthetic active radiation (IPAR ), air relative humidity $(R H)$, rainfall (Ppt) and evaporation (Evap) during the Summer and Autumn periods

\begin{tabular}{lccccccc}
\hline $\begin{array}{l}\text { Época } \\
\text { Season }\end{array}$ & $\operatorname{Tmax}\left({ }^{\circ} \mathrm{C}\right)$ & $\operatorname{Tmed}\left({ }^{\circ} \mathrm{C}\right)$ & $\operatorname{Tmin}\left({ }^{\circ} \mathrm{C}\right)$ & $\operatorname{Rad} \operatorname{Inc}\left(\mathrm{MJ} \mathrm{m}^{-2}\right)$ & $\mathrm{UR}(\%)$ & $\operatorname{Ppt}(\mathrm{mm})$ & $\operatorname{Evap}(\mathrm{mm})$ \\
\hline $\begin{array}{l}\text { Verão } \\
\text { Summer }\end{array}$ & $30,22 \pm 2,2$ & $25,50 \pm 1,7$ & $20,78 \pm 1,4$ & 17,21 & $80,86 \pm 8,4$ & 460,1 & 135,6 \\
$\begin{array}{l}\text { Outono } \\
\text { Autumn }\end{array}$ & $31,85 \pm 1,6$ & $26,20 \pm 1,3$ & $20,48 \pm 1,3$ & 17,55 & $72,46 \pm 8,8$ & 144,7 & 248,0 \\
\hline
\end{tabular}

Verão (Summer) - 15/01/2002 - 06/03/2002; Outono (Autumn) 04/03/2002 - 16/04/2002 
colmo. Uma subamostra de cada componente foi seca em estufa de ventilação forçada a $65^{\circ} \mathrm{C}$ e pesada. A partir dos dados obtidos, estimou-se a massa verde total (BVT) de lâmina foliar (BF) e de colmo (BC). A área foliar do restante da amostra de lâminas foliares foi estimada como o produto da área foliar específica pelo peso seco da fração de lâminas foliares.

Antes das amostragens destrutivas, foram efetuadas leituras da interceptação de radiação fotossinteticamente ativa (IRFA) e do índice de área foliar (IAF) nos pontos de amostragem, utilizando-se o sistema de análise de dossel - SUNSCAN (Delta-T, Cambridge, Inglaterra). Para obtenção da eficiência de uso da radiação (EUR), ajustou-se uma regressão linear entre os valores de RFAd interceptada e BT.

A dinâmica do perfilhamento ao longo da rebrotação foi acompanhada em três touceiras representativas de cada piquete; quatro anéis de PVC de seis polegadas de diâmetro foram posicionados em cada uma das três touceiras. Nesses anéis, foi monitorada a evolução semanal de desenvolvimento e morte de perfilhos, que eram identificados com anéis coloridos.

Aos dados de BTV e área foliar (AF) foram ajustados modelos polinomiais de segundo grau em função da idade do dossel, ao tempo das amostragens. Em seguida, a partir da derivada primeira da equação quadrática ajustada aos da BTV em função da idade, estimaram-se os valores instantâneos para a taxa de crescimento relativo (TCR) e a taxa de assimilação líquida (TAL), conforme Radford (1967), pelas fórmulas:

$$
\begin{aligned}
& \text { TCR } \frac{1}{\mathrm{~W}} \mathrm{u} \frac{\mathrm{dW}}{\mathrm{dt}} ; \\
& \text { TAL } \frac{1}{\mathrm{AF}} \mathrm{u} \frac{\mathrm{dW}}{\mathrm{dt}},
\end{aligned}
$$

em que $\mathrm{W}=$ valor instantâneo da massa de forragem verde seca, estimado a partir da respectiva equação quadrática $\left(\mathrm{g} \mathrm{m}^{-2}\right) ; \mathrm{AF}=$ valor instantâneo da área foliar ( $\mathrm{m}^{2}$ folha $\mathrm{m}^{-2}$ solo), estimado a partir da respectiva equação quadrática; $\mathrm{dW} / \mathrm{dt}$ = equação derivada primeira da respectiva equação quadrática da massa de forragem verde seca em função do tempo de rebrotação $\left(\mathrm{g} \mathrm{m}^{-2} \cdot \operatorname{dia}^{-1}\right)$.

$\mathrm{O}$ valor instantâneo da razão de área foliar (RAF) foi calculado com base no quociente entre os valores de AF e BTV relativos a cada idade. Às estimativas de TCR, TAL e RAF foram ajustadas equações de acordo com as respectivas idades de amostragem.

\section{Resultados e Discussão}

Os dados climáticos relativos ao período de avaliação de cada dossel não refletiram a real diferença entre verão e outono quanto à maioria das variáveis de ambiente avaliadas. A grande diferença entre os dois períodos se restringiu à precipitação pluvial e à evaporação.

A emissão de novas folhas pelos meristemas terminais dos perfilhos não decapitados e o desenvolvimento de novos perfilhos constituem os processos de reconstituição da área foliar do dossel durante o período de descanso. Em ambos os períodos avaliados (verão e outono), o IAF do piquete de capim-mombaça evoluiu segundo um padrão assintótico de resposta à duração do período de descanso (Figura 1), observando-se, entretanto, valores de IAF mais altos no verão que no outono.

A diferença nos valores de IAF entre o verão e outono deve ser atribuída principalmente à mais alta pluviosidade no verão, à maior evaporação no outono (Tabela 1) e à maior biomassa residual inicial da área avaliada no verão. A perda de turgescência celular em resposta à queda no potencial hídrico do solo (Taiz \& Zeiger, 1998) reduz a taxa de alongamento foliar (Mattos et al., 2005) afetando, conseqüentemente, o tamanho da folha e área foliar da planta. Portanto, é importante enfatizar o acentuado incremento do IAF no verão (aproximadamente 8,0 ), que foi praticamente o dobro do observado no outono (em torno de 4,0).

Diferentemente da IAF, a evolução da IRFA (Figura 2) não apresentou diferença apreciável entre os períodos estudados. Embora a IRFA tenha sido inicialmente mais alta no verão (Figura 2), esta diferença se inverteu com o decorrer da reconstituição da área foliar da gramínea. Verificou-se evolução assintótica, com tendência de estabilização em torno de $95 \%$, após o $35^{\circ}$ dia do período de descanso, em ambas as estações, apesar do menor valor de IAF final alcançado no outono. Esse padrão de evolução da intercepção da radiação está de acordo com a estabilização da radiação pouco acima de $95 \%$ no 33 은 dia de descanso do capim-tânzania relatada por Mello \& Pedreira (2004).

A ausência de diferença na IRFA decorreria da grande variação do IAF, decorreria da diferença entre as áreas avaliadas no verão e outono quanto às suas características estruturais iniciais de altura e cobertura do solo, mais altas na área avaliada no verão que na avaliada no outono. Assim, o dossel

\section{R. Bras. Zootec., v.34, n.6, p.2164-2173, 2005 (supl.)}




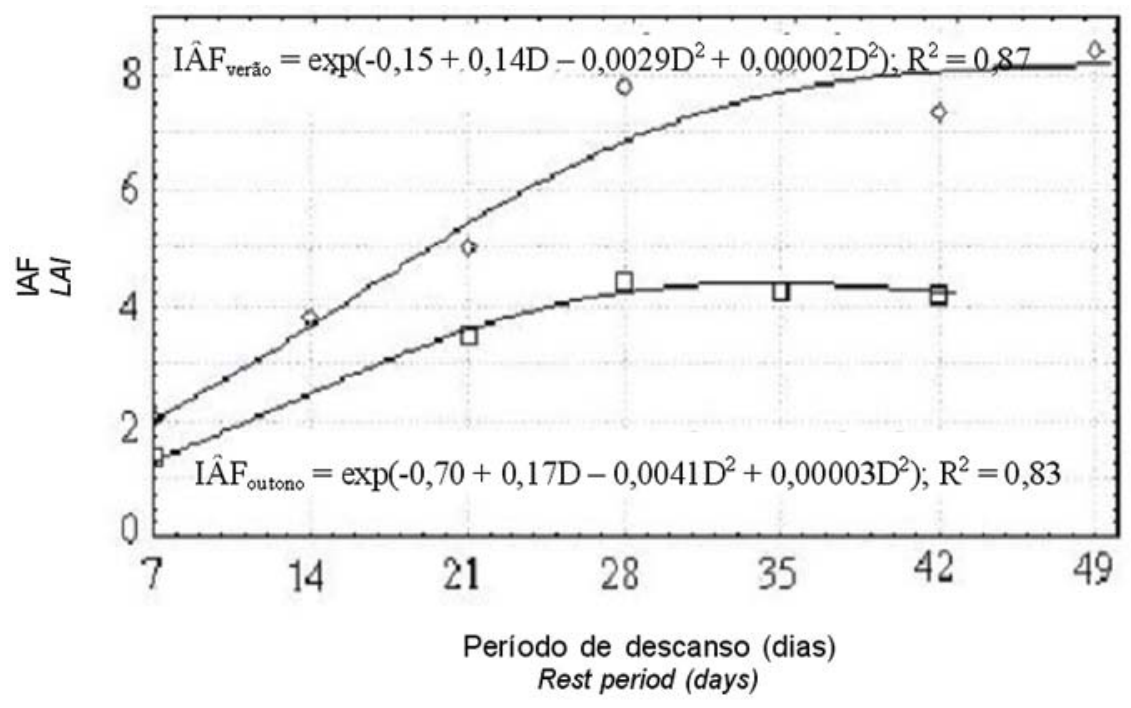

Figura 1 - Índice de área foliar (IAF) do capim-mombaça durante a rebrotação no verão e no outono.

Figure 1 - Evolution of the leaf area index (LAI) in mombaçagrass paddock during the Summer and Autunm regrowths.

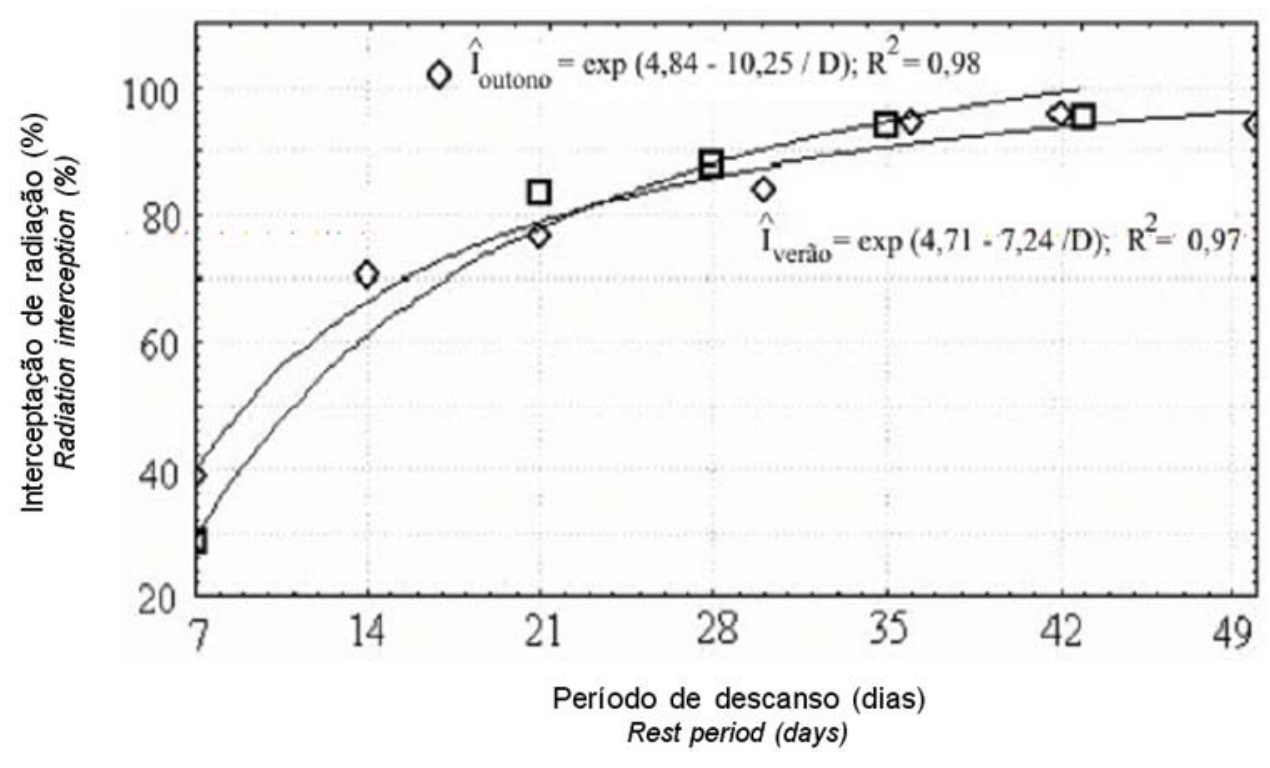

Figura 2 - Evolução da interceptação da radiação fotossinteticamente ativa do capim-mombaça durante a rebrotação no verão e outono.

Figure 2 - Evolution of the photosynthectic active radiation interception by mombaçagrass canopy during the Summer and Autumn regrowyhss.

avaliado no verão apresentava-se mais ereto, enquanto a vegetação do outono desenvolveu folhas mais horizontais, com mais alto coeficiente de extinção e, portanto, maior eficiência de interceptação de luz, conforme Sheehy e Cooper (1973) e Sugiyama et al. (1985). Contudo, estas características são dependentes da resposta do dossel, e, portanto, seu efeito é mais evidente no final do período de crescimento, pois o maior valor de IAF no início do verão determina maior IRFA, que se estende até aproximadamente os 21 dias do período de crescimento (Figura 2).

Registraram-se intenso perfilhamento nas duas primeiras semanas do período de rebrotação (Figura 3) e drástica redução após a terceira semana, quando o dossel apresentava IAF em torno de 3,58 a 4,23 (Figura 1), interceptando aproximadamente $90 \%$ da

R. Bras. Zootec., v.34, n.6, p.2164-2173, 2005 (supl.) 
radiação fotossinteticamente ativa (Figura 2). Observou-se também, entre a primeira e segunda semanas, uma redução da população dos perfilhos existentes nos piquetes no início do período de rebrotação.

A radiação luminosa incidente sobre a superfície do dossel, mais intensa e constituída de todas as ondas do espectro solar, é interceptada pelas sucessivas camadas de folhas à medida que permeia pelo perfil do dossel, de maneira preferencial na faixa do azul e vermelho (Sugiyama et al., 1985). Assim, a luminosidade que alcança a base do dossel é fraca e de estreita relação vermelho/vermelho extremo (v/ve), condição que inibe o desenvolvimento das gemas basilares em perfilhos. Resultados experimentais descritos por Deregibus et al. (1985) e Wan Sosebee (1998) evidenciam alta e direta associação do perfilhamento com a relação v/ve do ambiente luminoso no nível do solo. Korte et al. (1982) relataram comprometimento do perfilhamento em relvado de azevém perene (Lolium perenne) interceptando quase toda luz incidente.

O maior acúmulo de biomassa verde total observado durante o verão decorreria das mesmas razões para a evolução do IAF; isto é, melhores condições de pluviosidade e biomassa residual mais alta no verão que no outono.

Visto que as estimativas de biomassa resultam de amostras realizadas a $20 \mathrm{~cm}$ do solo, deve-se admitir que a biomassa no verão é superestimada, pois inclui boa parte da biomassa residual após pastejo inicial, principalmente aquela relativa às primeiras semanas.

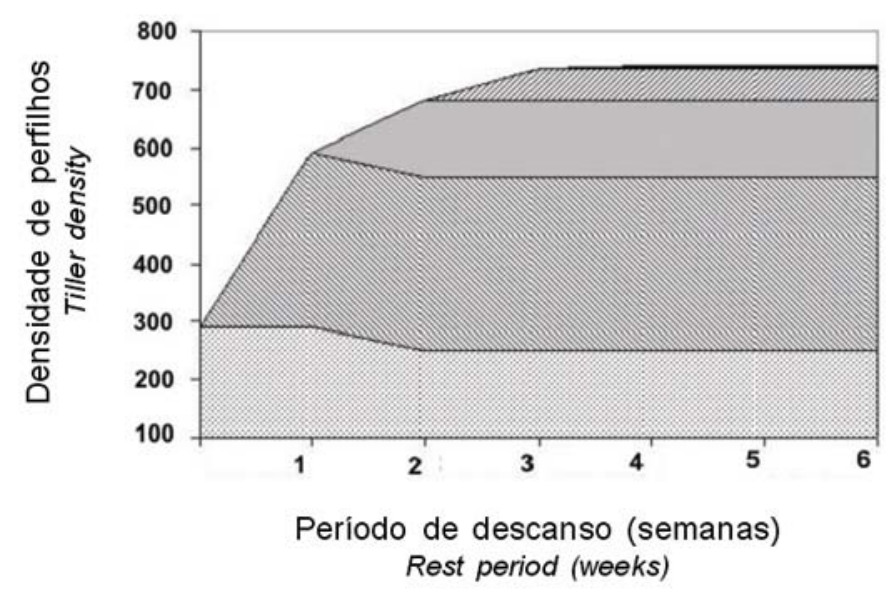

Figura 3 - Evolução do perfilhamento do capim-mombaça durante a rebrotação no outono.

Figure 3 - Tillering evolution in mombaçagrass in the Autumn regrowth
De qualquer modo, é valida a constatação de maior acúmulo de forragem no verão.

A massa de forragem verde total (BTV) do capim-mombaça apresentou evolução em um padrão quadrático (Figura 4).

O acúmulo de biomassa verde total no dossel resulta da eficiência de interceptação da luz incidente pelo dossel, do diferencial entre a expansão de novas folhas, do desenvolvimento de novos perfilhos, da senescência e morte de perfilhos e da intensidade do processo de alongamento de colmos no dossel.

$\mathrm{Na}$ fase inicial da rebrotação, o incremento de biomassa decorre principalmente das novas folhas expandidas e dos novos perfilhos desenvolvidos. Todavia, à medida que o dossel se fecha interceptando quase toda a radiação luminosa incidente, intensifica-se o processo de senescência e morte das folhas mais velhas, ao mesmo tempo em que o perfilhamento é inibido. Nestas condições, o processo de perfilhamento é substituído pelo de alongamento de colmo, propiciando a continuação do incremento de massa no dossel fechado. Ocorreria, assim, alteração na partição de fotoassimilados para a formação de colmo em detrimento do perfilhamento. De fato, o acúmulo de biomassa de colmo aumentou linearmente durante a rebrotação, no verão. $\mathrm{O}$ alongamento de colmo é estimulado por fatores que inibem o perfilhamento (Jewiss, 1972), entre eles o sombreamento (Smith, 1982; Korte et al., 1982).

O alongamento do colmo, que propicia a alteração na estrutura do dossel, é caracterizado pelo
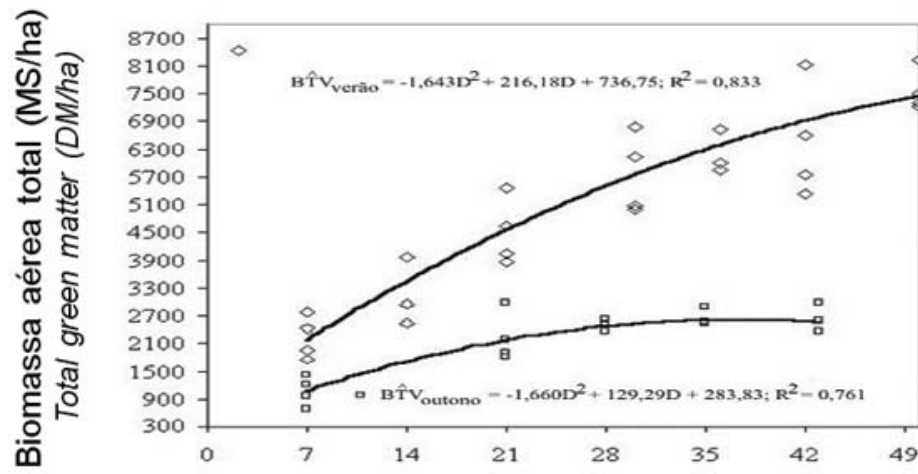

Período de descanso (dias) Rest period (days)

Figura 4 - Acúmulo de biomassa de forragem verde total do capim-mombaça durante rebrotação no verão e outono.

Figure 4 - Total green forage biomass accumulation in mombaçagrass during the Summer and Autumn regrowth.

R. Bras. Zootec., v.34, n.6, p.2164-2173, 2005 (supl.) 
distanciamento entre as folhas do perfilho e pelo aumento do ângulo foliar em relação ao solo. Com essas características, o dossel tem seu coeficiente de extinção de luz reduzido e, portanto, apresenta menor capacidade de interceptação da radiação luminosa (Sugiyama et al., 1985; Sheehy \& Cooper, 1973). Essas condições, favorecendo a penetração da luz, prolongam o período em que a IRFA permanece estável, abaixo do valor máximo (100\%). Como resultado, a fotossíntese líquida do dossel é favorecida, propiciando amento da massa de colmo sob condições de dossel quase fechado.

A exemplo do IAF, também se foram observadas diferenças entre verão e outono para biomassa total verde (Figura 4), colmo (Figura 5) e folhas (Figura 6). A restrição hídrica no outono teria resultado na síntese de ácido abscísico a partir dos carotenóides do sistema radicular, estimulando a senescência e morte de folhas, além de redução na produção da massa aérea em benefício do sistema radicular (Larcher, 1995). Além disso, o comprometimento da distribuição da radiação fotossinteticamente ativa pelo perfil do dossel, em razão do pequeno alongamento de colmo, cria condições de luminosidade abaixo do ponto de compensação de luz, induzindo a senescência e morte foliares.

Os altos valores de biomassa de colmo no verão também devem ser considerados com cautela, pois seus valores iniciais estariam também superestimados pelas mesmas razões que a biomassa verde total.

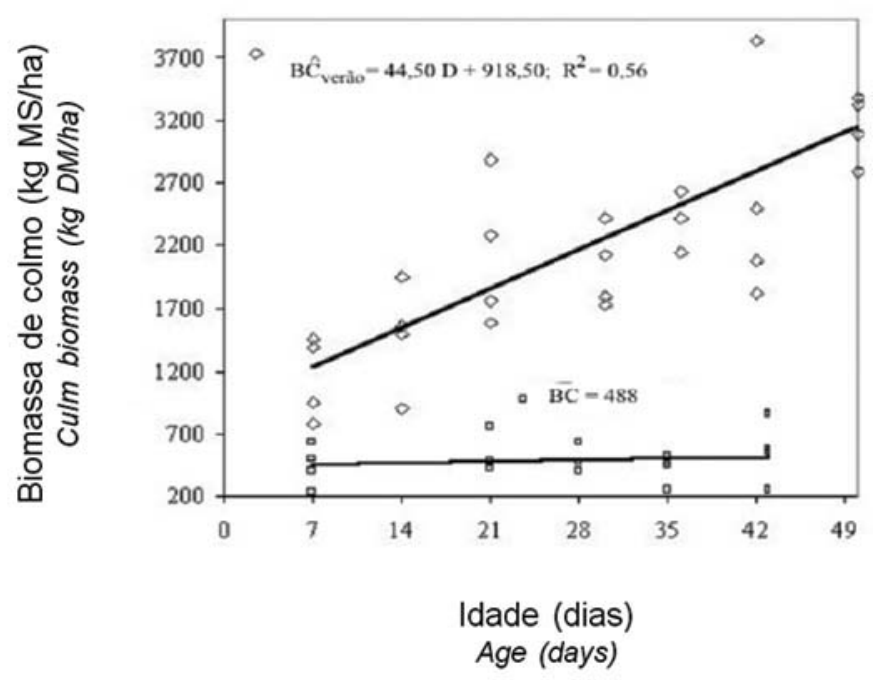

Figura 5 - Acúmulo de biomassa de colmo do capimmombaça no verão e outono.

Figure 5 - Culm biomass accumulation in mombaçagrass during the Summer and Autumn.
De qualquer maneira, a estimativa média de $44,5 \mathrm{~kg} /$ ha/dia de aumento de biomassa de colmo no verão pode ser considerada confiável.

Diferentemente das estimativas de biomassa verde total e de colmo, não se acredita em superestimativa na biomassa de folha (Figura 6), pois a contribuição das massas de folhas residuais ao início de cada crescimento era mínima. O crescimento do dossel foi maior no verão, observando-se biomassa próxima a 4.000 e $2.000 \mathrm{~kg} / \mathrm{ha}$ após o $42^{\circ}$ dia de descanso no verão e no outono, respectivamente.

Consta na Figura 7 a relação entre a biomassa verde total e a quantidade acumulada de radiação fotossinteticamente ativa interceptada ( $\sum \mathrm{RFAI}$ ). Observou-se que o acúmulo de biomassa em resposta à somatória da radiação interceptada foi acentuadamente mais elevado no verão que no outono. $\mathrm{O}$ coeficiente angular da equação linear ajustada aos dados de biomassa verde total em função da $\sum$ RFAI representa a eficiência de uso da radiação (EUR). Os coeficientes angulares foram de 1,76 e 0,54 gMS/MJ, respectivamente, para o verão e outono. As diferenças observadas são atribuídas aos mesmos fatores que determinaram a maior biomassa verde total no verão, principalmente a maior precipitação.

A reduzida precipitação durante o outono teria resultado em estresse hídrico, aumentando a resistência estomática e comprometendo a capacidade fotossintética do dossel (Mattos et al., 2005). Além disso, a redução de $69,3 \%$ da EUR pode ter sido, em

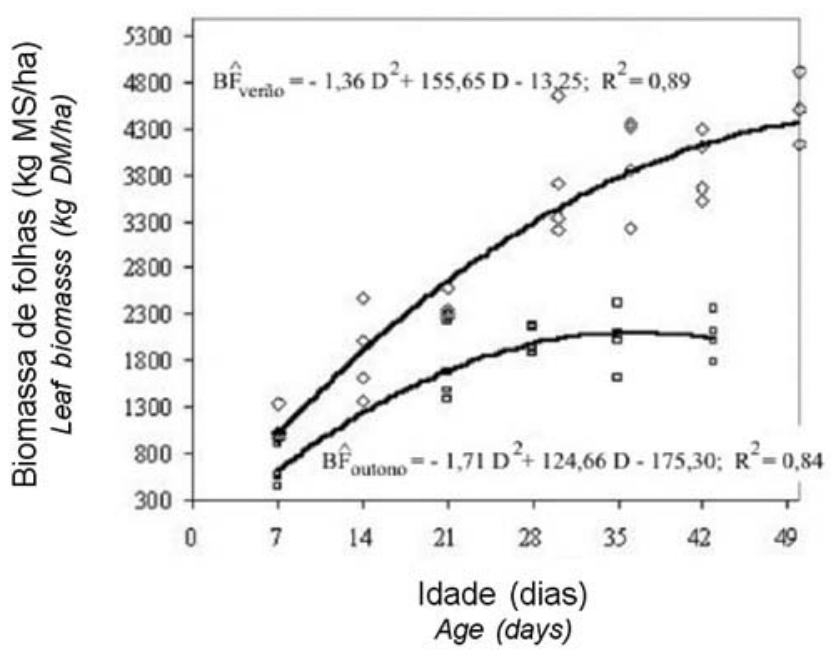

Figura 6 - Acúmulo de biomassa de folhas verdes do capim-mombaça no verão e outono.

Figure 6 - Green leaf biomass accumulation in Mombaçagrass during the Summer and Autumn. 


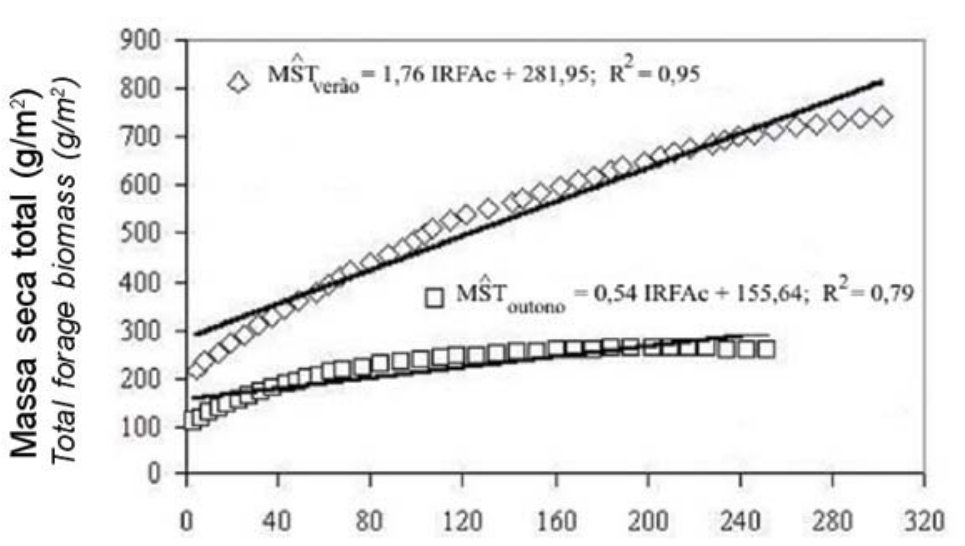

Radiação fotossinteticamente ativa acumulada $\left(\mathrm{MJ} / \mathrm{m}^{2}\right)$ Accumulated photosynthetic active radiation $\left(\mathrm{MJ} / \mathrm{m}^{2}\right)$

Figura 7 - Relação entre a biomassa de forragem verde e a radiação fotossinteticamente ativa interceptada acumulada no verão e outono.

Figure 7 - Relationship between green forage biomass of mombaçagrass and accumulated photossynthetic active radiation during the Summer and Autumn.

parte, influenciada pela partição de assimilados em benefício do sistema radicular, reduzindo a relação parte aérea/raiz em plantas submetidas a estresse hídrico, conforme observado em capim do gênero Cynodon(Oliveira, 2002).

A EUR registrada no verão foi bastante inferior ao valor médio de 2,5 gMS/MJ relatado por Le Roux et al. (1997) para cultura de metabolismo $\mathrm{C}_{4}$. Entretanto, a EUR varia ao longo do ciclo da planta, em razão de alterações no número de novas folhas, na taxa fotossintética e na respiração das folhas ou de mudança na partição de assimilados, no estádio fisiológico da vegetação, na umidade do solo e na adubação (Le Roux et al., 1997).

A taxa de crescimento relativo (TCR) do dossel de capim-mombaça (Figura 8) decresceu durante o período de rebrotação segundo um padrão assintótico apenas no verão, confirmando os resultados obtidos por Cândido et al. (2005) para a mesma gramínea.

Vários fatores, como espécie ou cultivar (Ludlow \& Wilson, 1970), estádio de crescimento e condições de ambiente, influenciam a TCR das culturas, pelos seus efeitos sobre a RAF e TAL.

Verificou-se proximidade dos valores de TCR no início de ambos os períodos de rebrotação, no verão e outono. Entretanto, posteriormente, as curvas se afastaram, em razão da mais rápida queda da TCR no outono, refletindo os efeitos negativos das condições de ambiente, principalmente as limitações hídricas

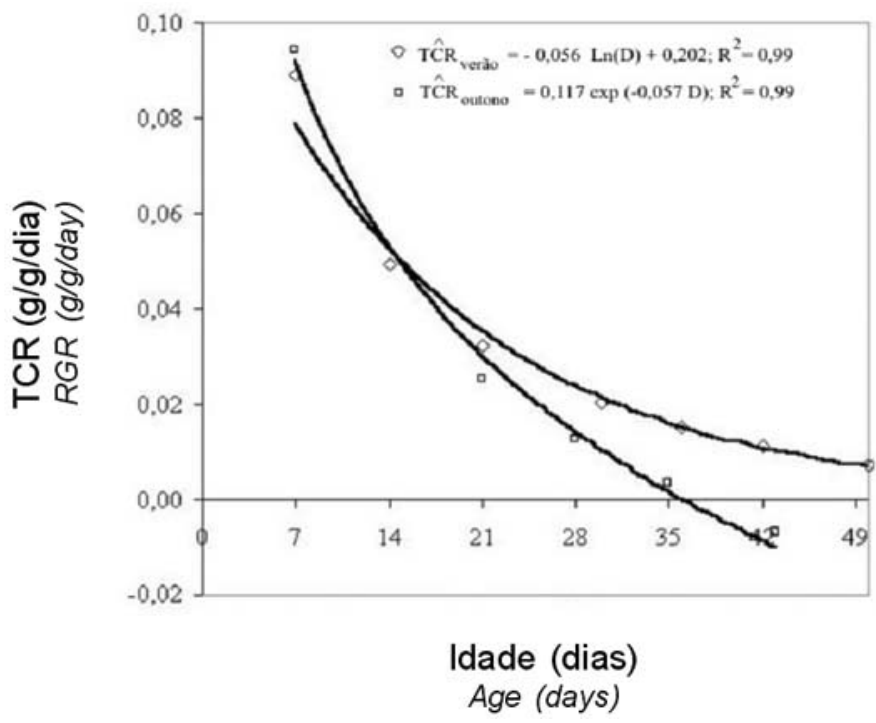

Figura 8 - Taxa de crescimento relativa (TCR) do capimmombaça durante no verão e outono.

Figure 8 - Relative growth rate (RGR) of mombaçagrass during the Summer and Autumn.

(Tabela 1). Essa queda da TCR no decorrer do período de rebrotação pode ser atribuída ao progressivo incremento no peso da planta, uma vez que a $\mathrm{TCR}=(1 / \mathrm{W}) .(\mathrm{dW} / \mathrm{dt})$, assim como da diminuição nos valores de TAL e RAF, visto que a TCR resulta do produto destes dois índices de crescimento: o primeiro, um componente fisiológico e o segundo, um componente morfológico.

Houve queda nos valores da TAL, segundo um padrão aproximadamente assintótico, no verão (Figura 9). Relatos semelhantes foram observados por Cândido et al. (2005) e Oliveira et al. (2000), em estudo com capim-mombaça e capim-bermuda Tifton 85 , respectivamente. Os mais altos valores iniciais de TAL, 7,6 e $8,1 \mathrm{~g} \mathrm{MSm}^{-2} \mathrm{dia}^{-1}$, respectivamente no verão e outono, são semelhantes àqueles obtidos para o capim-mombaça em rebrotação depois de roçada no período de novembro-dezembro (Cândido et al., 2005) e em casa de vegetação (Gomide et al., 2003).

A diminuição da TAL no decorrer da rebrotação pode ser atribuída à queda na capacidade fotossintética líquida do dossel, ocasionada pelo avanço da idade média de sua área foliar e do sombreamento mútuo das folhas (Woledge, 1977), e ao aumento da carga respiratória da planta, fatores que comprometem a fotossíntese líquida do dossel.

Os valores de RAF apresentaram grande variação ao longo do período de rebrotação, com valores de 0,0093 a 0,0120 e de 0,0129 a $0,0167 \mathrm{~m}^{2} \mathrm{~g}^{-1}$ (Figura 10), 


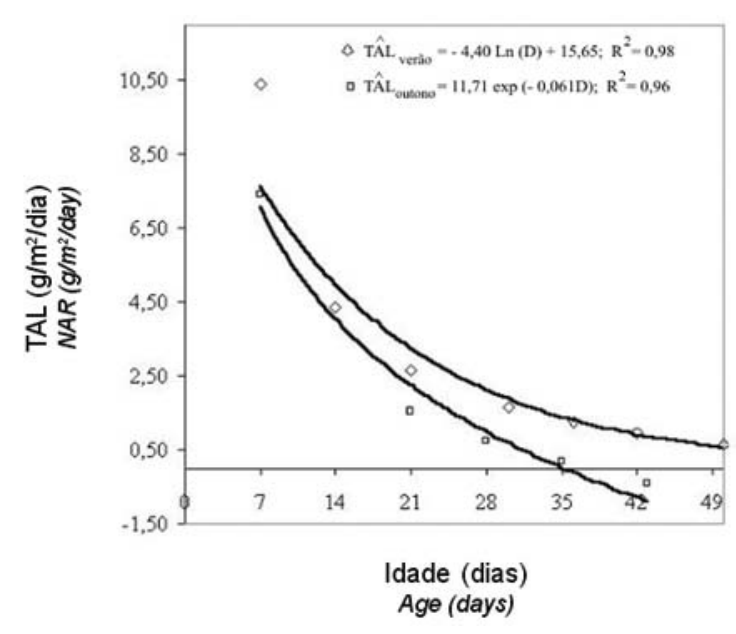

Figura 9 - Taxa assimilatória líquida (TAL) do capimmombaça no verão e outono.

Figure 9 - Net assimilation rate (NAR) of mombaçagrass in the Summer and Autumn.

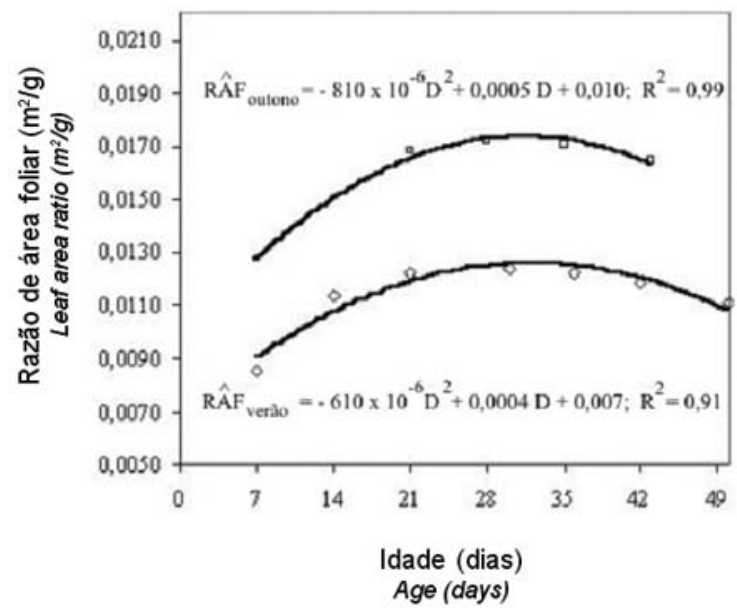

Figura 10 - Razão de área foliar do capim-mombaça no verão e outono.

Figure 10 - Leaf area ratio of mombaçagrass in the Summer and Autumn.

respectivamente, para o verão e outono, mas são semelhantes àqueles relatados por Cândido et al. (2005), Gomide et al. (2003) e Oliveira et al. (2000), que apresentaram também grande variação nos valores de RAF no decorrer da rebrotação.

Os valores de RAF, mais altos no outono que no verão, variaram ao longo do período de rebrotação segundo um padrão de resposta quadrática (Figura 10). Esse efeito não condiz com a suspeita de ocorrência de déficit hídrico na área experimental durante o outono, pois este déficit tenderia a ocasionar queda na RAF (Oliveira, 2002), em decorrência de um comprometimento na turgescência celular e, portanto, na expansão foliar. Contudo, esse efeito provavelmente deve ter sido mascarado pela condição inicial de estrutura e massa do dossel no verão, em que o maior resíduo de forragem pós-pastejo acarretou maior quantidade de colmo (Figura 5), e portanto, menores valores de RAF.

Tanto no verão como no outono, a RAF cresceu inicialmente e diminuiu posteriormente, após alcançar máximo valor por volta do $28^{\circ}$ dia de rebrotação. Os crescentes valores da RAF na fase inicial foram ocasionados pela grande massa residual de colmo do dossel ao início do crescimento, resultando em excesso de massa de colmo decorrente da amostragem a $20 \mathrm{~cm}$ do solo em relação à área foliar das novas folhas formadas durante as primeiras semanas do período. Assim, os valores de RAF se apresentaram inicialmente crescentes, conforme observado por Gomide et al. (2003), em estudo da rebrotação do capim-mombaça cultivado em vasos, após corte a $8 \mathrm{~cm}$, às idades de 16 e 37 dias pósemergência. Diferentemente dos fatos relatados, o padrão de evolução da RAF foi, desde o início, decrescente e assintótico em estudo desse cultivar em vaso, cortados rente ao solo (Gomide \& Gomide, 1999) e do capim-tifton 85 , em estudo de parcelas a campo, também cortado rente ao solo (Oliveira et al., 2000).

Embora a RAF seja, segundo Poorter (1989), fator determinante da TCR mais importante que a TAL (TCR $=$ RAF x TAL), neste estudo, os valores de TCR apresentaram melhor relação com os de TAL, pois ambas as variáveis apresentaram padrões de variação semelhantes, decrescentes segundo uma resposta assintótica, enquanto a RAF mostrou um padrão de resposta quadrática com ponto de máximo.

\section{Conclusões}

Os valores de índice de área foliar e interceptação da radiação fotossintéticamente ativa, mais altos no verão que no outono, indicam um padrão assimptótico de evolução crescente com o decorrer do período de rebrotação estudado.

O perfilhamento do capim-mombaça, intenso nas três primeiras semanas de rebrotação, é inibido pelo progressivo sombreamento do estrato inferior do dossel. 
Sob condições de dossel fechado, a biomassa de colmo responde pela maior parte do acúmulo de biomassa verde total da gramínea. O fluxo de biomassa de folhas e de colmos foi menos intenso no outono.

A eficiência de uso da radiação no verão foi o triplo daquela observada no outono.

As taxas de crescimento relativo e de assimilação líquida apresentaram padrão assintótico negativo de evolução, alcançando valores finais de $0,01 \mathrm{~g} / \mathrm{g} / \mathrm{dia} \mathrm{e}$ $0,7 \mathrm{~g} / \mathrm{m}^{2} / \mathrm{dia}$, respectivamente, no verão e valores negativos no outono.

O comprometimento do processo de perfilhamento e a queda nas taxas de crescimento relativo e de assimilação líquida são alguns dos fatores limitantes do acúmulo de forragem ao final de prolongado período de rebrotação.

\section{Literatura Citada}

BEADLE, C.L. Growth analysis. In: HALL, D.O.; BOLHARNORDENKAMPF, H.R.; LEEGOOD, R.C. et al. (Eds.). Photosynthesis and production in a changing environment. London: Pergamon Press, 1993. p.36-45.

CÂNDIDO, M.J.D.; ALEXANDRINO, E.; GOMIDE, J.A. Duração do período de descanso e crescimento do dossel de Panicum maximum cv Mombaça sob lotação intermitente. Revista Brasileira de Zootecnia, v.34, n.2, p.398-405, 2005.

DEREGIBUS, V. A.; SANCHES, R. A.; CASAL, J. J. et al. Tillering responses to enrichment of red light beneath the canopy in a humid natural grassland. Journal of Applied Ecology, v.22, n.1, p.199-206, 1985.

GOMIDE, C.A.M.; GOMIDE, J.A.; ALEXANDRINO E. Índices morfogênicos e de crescimento durante o estabelecimento e a rebrotação do capim-Mombaça (Panicum maximum Jacques). Revista Brasileira de Zootecnia, v.32, n.4, p.795-803, 2003.

GOMIDE, C.A.M.; GOMIDE, J.A. Análise de crescimento de cultivares de Panicum maximum Jacq. Revista Brasileira de Zootecnia, v.28, n.4, p.675-680, 1999.

JEWISS, O.R. Tillering in grasses. Its significance and control. Journal British Grassland Society, v.27, n.1, p.65-82. 1972.

KORTE, C.J.; WATKIN, B.R.; HARRIS, W. Use of residual leaf area index and light interception as criteria for springgrazing management of ryegrass dominant pasture. New Zealand Journal of Agricultural Research, v.25, n.3, p.309-319, 1982.

LAMBERS, H. Does variation in photosynthetic rate explain variation in growth rate and yield? Netherlands Journal of Agricultural Science, v.35, n.4, p.505-519, 1987.

LARCHER, W. Physiological plant ecology. 3.ed. Berlin: Springer Verlage, 1995. 506p

LE ROUX, X.; GAUTHIER, H.; BÉGUÉ, A. et al. Radiation absorption and use by humid savanna grassland:assessment using remote sensing and modelling. Agricultural and Forest Meteorology, v.85, n.1-2, p.117-432, 1997.

LEMAIRE, G. The physiology of grass growth under grazing: tissue turnover. In: SIMPÓSIO INTERNACIONAL SOBRE PRODUÇÃO ANIMAL EM PASTEJO, Viçosa, MG, 1997.
Anais... Viçosa, MG: Universidade Federal de Viçosa, 1997. p.115-144.

LUDLOW, M.M.; WILSON, G.L. Studies on the productivity of tropical pasture plants. II. Growth analysis, photosynthesis, and respiration of 20 species of grasses and legumes in a controlled environment. Australian Journal of Agricultural Research, v.21, n.2, p.183-194, 1970.

MATTOS, J.L.S.; GOMIDE, J.A.; MARTINEZ, C.A. Crescimento de espécies do gênero Brachiaria sob déficit hídrico, em casa de vegetação. Revista Brasileira de Zootecnia, v.34, n.3, p.746-754, 2005.

McKENZIE, B.A.; KEMP, P.D.; MOOT, D.J. et al. Environment effects on plant growth and development. In: WHITE, J.; HODGSON, J. (Eds.) New Zealand pasture and crop science. Oxford: Oxford University Press, 1999. p.29-44.

MELLO, A.C.L.; PEDREIRA, C.G.S. Respostas morfológicas do capim-tanzânia ( Panicum maximum Jacq cv Tanzânia-1) irrigado à intensidade de desfolha sob lotação ratacionada. Revista Brasileira de Zootecnia, v. 33, n.2, p.282-289, 2004.

OLIVEIRA, M.A. Características morfofisiológicas e valor nutritivo de gramíneas forrageiras do gênero Cynodon sob diferentes condições de irrigação, fotoperíodo, adubação nitrogenada e idades de rebrota. Viçosa, MG: Universidade Federal de Viçosa, 2002. 142p. Tese (Doutorado em Zootecnia) - Universidade Federal de Viçosa, 2002.

OLIVEIRA, M.A.; PEREIRA, O.G., GOMIDE, J.A. Análise de crescimento do capim bermuda "Tifton 85" (Cynodon spp). Revista Brasileira Zootecnia, v.29, n.6, p.1930-1938, 2000.

PEARCE, R.B.; BROWN, R.H.; BLASER, R.E. Relationships between leaf area index, light interception and net photosynthesis in orchardgrass. Crop Science, v.5, n.6, p.533-556, 1965.

POORTER, H. Interspecific variation in relative growth rate: on ecological causes and physiological consequences. In: LAMBERS, H. et al. (Eds.) Causes and consequences of variation in growth rate and productivity of higher plants. The Hague: Academic Publishing, 1989. p.45-68.

RADFORD, P.J. Growth analysis formulae - their use and abuse. Crop Science, v.7, n.3, p.171-175, 1967.

SHEEHY, J.E.; COOPER, J.P. Light interception, photosynthetic activity, and crop growth rate in canopies of six temperate forage grasses. Journal of Applied Ecology, v.10, n.1, p.239-249, 1973.

SMITH, H. Light quality, photoperception, and plant strategy. Annual Review of Plant Physiology, v.33, p.481-518, 1982.

SUGIYAMA, S.; YONEYAMA, M.; TAKAHASHI, N. et al. Canopy structure and productivity of Festuca arundinacea Schreb. swards during vegetative and reproductive growth. Grass and Forage Science, v.40, n.1, p.49-55, 1985.

TAIZ, L.; ZEIGER, E. Plant physiology. 2.ed. Sunderland: Sinauer Associates, 1998. 792p.

VIANELLO, R.L.; ALVES, A.R. Meteorologia básica e aplicações. Viçosa, MG: Universidade Federal de Viçosa, 2000. 448p.

WAN, C.; SOSEBEE, R.E. Tillering responses to red:far-red light ratio during different phenological stages in Eragrostis curvula. Environmental and Experimental Botany, v.40, n.3, p.247254, 1998.

WOLEDGE, J. The effects of shading and cutting treatments on the photosynthetic rate of ryegrass leaves. Annals of Botany, v.41, n.176, p.1279-1286, 1977.

Recebido em: 01/12/04

Aceito em: 04/08/05 